\title{
Diagonal Mergers and Foreclosure in the Internet
}

\author{
EMANUELE GIOVANNETTI *
}

Faculty of Economics, University of Cambridge and University of Rome "La Sapienza"

\begin{abstract}
We study the incentives for a "diagonal" merger between two Internet Service Providers, one a wireless retail only ISP in two origination markets, and the second a vertically integrated wired retailer in one market and an upstream provider in the other. The merger's effects depend on differentiation in access modalities; only with high differentiation does the merger have positive welfare effects. We focus on post-merger foreclosure, which, when it happens, only takes place in the market where the merger is horizontal and not where the merger is vertical. The Network architecture used is meant to capture Internet routing.
\end{abstract}

\section{Introduction}

\subsection{Pricing and foreclosure in networks}

The problem of pricing the access to an essential facility is one of the identifying issues of the economics of networks. For a network composed of one-way links, as in electricity transmission, the access price, if not regulated, is usually defined between who buys and who sells the access to a given production input. This process usually takes place along a vertical hierarchy, often under monopoly conditions.

With a two-way links network, as in mobile telephony, each one of the two firms at the edge of the link should pay for the price of access to the essential input of the other firm, its customer base. In this last case, network transactions unfold along a horizontal hierarchy, with the two firms having reciprocal market power on each other. One added element of interest is that, often firms requiring reciprocal access to a network component also compete against each other in the retail market for their customer base. A vast literature dealing with access prices (both for horizontal and vertical relations) in strategic settings mainly related to telephony problems, and the analysis of its effects on social

\footnotetext{
* Faculty of Economics, Austin Robinson Building, Sidgwick Avenue, Cambridge, CB3 9DE. Email: E.giovannetti@econ.cam.ac.uk The author thanks funding from the EU FP6 Action "Competition, Contents and Broadband for the Internet in Europe" CoCombine IST-2004-2012 and from the Isaac Newton Trust, Trinity College, University of Cambridge. I would also like to thank Frank Kelly and David Newbery for early discussions, Alessio D'Ignazio and an anonymous referee for valuable suggestions, participants at ESEM 2003 session on Mergers and Beth Morgan and Anne Mason for helping with careful reading. The usual disclaimer applies.
} 
welfare and competition policy, is detailed in Laffont and Tirole (2003) and Armstrong (2002).

In both cases (vertical or horizontal hierarchy), firms may use access pricing to deny access to the essential input they produce, creating market foreclosure. In the case of vertical relations, foreclosure is adopted to extend monopoly power on the downstream market; in the case of horizontal relations, foreclosure may result in a cooperation network with a dominant group architecture (Goyal and Joshi, 2003).

Foreclosure in Networks may follow different patterns where pricing access is not the key element (Rey and Tirole, forthcoming). This is particularly true in the specific context of the Internet where the access problem has been initially addressed by Crèmer et al. (2000). The authors consider a two-stage game and describe a strategy of non-price foreclosure by introducing a choice about the level of interconnection quality between two backbones. With unequal market shares, the best strategy for the backbone with the most customers is offering a low quality of interconnection to the other one; this leads to market tipping and dominance by the largest backbone. Foros and Hansen (2001) introduced the hypothesis of horizontal differentiation between backbones via an Hotelling model with two operators, first deciding on interconnection quality and then engaging in price competition. Foros et al. (2004) extended the analysis of quality foreclosure for Internet backbone access to downstream rivals within an international regulatory game with Cournot competition in the retail market. Buccirossi (1999) framed the analysis of regulated access under different property rights regimes finding that, when access is regulated according to the efficient component pricing rule, one can even observe foreclosure of efficient suppliers.

The architecture of Networks used in the analysis is central in modelling the access problem and in predicting possible market results. Laffont et al. (2003) focus on competing Internet backbones where the relevant traffic flow is one way ${ }^{1}$ : from website to end users, both target customers for the backbones. The authors showed how retail prices in equilibrium just cover the opportunity cost from losing a final customer to the competitor, while upstream access prices determine the way web-sites and consumers share traffic costs. Using a different network architecture to capture the specificity of Internet routing, Giovannetti (2002) analysed the effects of network interconnection on prices, both retail and access. The mixed hierarchy introduced is of specific interest for the Internet where two providers can be, simultaneously, vertically related as supplier and retailer in a routing process, and horizontally competing for the routing of different traffic.

\subsection{Mergers and foreclosure in networks}

The late nineties witnessed a post-liberalization rush in merger activity in the telecommunication sector, in particular between fixed and wireless providers. The Table 1 below shows the ten largest complete takeovers between 1995 and 2000 having both acquirer and target in the telecommunications sector, Waverman and Trillas (2002).

\footnotetext{
${ }^{1}$ This usage of one way links is appropriate in modeling Internet exchanges because of the asymmetry between requests for downloads, which require small information transfers, and the more informationdemanding downloads.
} 


\begin{tabular}{|l|l|l|l|}
\hline Date & Acquirer & Target & $\begin{array}{l}\text { Value of } \\
\text { transaction } \\
\text { \$ million }\end{array}$ \\
\hline $1 / 10 / 1997$ & WorldCom Inc. & MCI Communications & 41.907 \\
\hline $11 / 5 / 1998$ & SBC & Ameritech & 62.592 \\
\hline $24 / 6 / 1998$ & AT\&T & Tele-Communications Inc & 53.592 \\
\hline $28 / 7 / 1998$ & Bell Atlantic & GTE & 53.415 \\
\hline $18 / 1 / 1999$ & Vodafone & AirTouch & 60.287 \\
\hline $22 / 4 / 1999$ & AT\&T & MediaOne Group & 49.279 \\
\hline $14 / 6 / 1999$ & Qwest & US West & 56.307 \\
\hline $14 / 11 / 1999$ & Vodafone AirTouch & Mannesmann & 202.785 \\
\hline $29 / 2 / 2000$ & Pacific Century & Cable \& Wireless & 37.442 \\
& Cyberworks & & 45.967 \\
\hline $30 / 5 / 2000$ & France Telecom & Orange & \\
\hline
\end{tabular}

Table 1: Largest takeovers in Telecommunications

Source: Thomson Mergers, from Waverman and Trillas (2002).

More recently, Sidak (2002) analysed Deutsche Telekom's acquisition of VoiceStream (wireless), in April 2001. Deutsche Telekom was Europe's largest telecommunications company and the third largest carrier worldwide who also acquired the wireless operator One to One in the United Kingdom.

The merger activity continues while writing: on the $23^{\text {rd }}$ of October 2004 the Justice Department of the United States approved the $\$ 41$ billion merger of Cingular Wireless and AT\&T Wireless Services. As a result Cingular, a joint venture of SBC Communications (wireless) and BellSouth (fixed) will overtake the previous market leader, Verizon, one of the largest providers of fixed and wireless communications in the US, and itself the result of the merger, in 2000, between Bell Atlantic and GTE. On the merger's announcement the Phoenix Center for Advanced Legal \& Economic Public Policy Studies analysed its likely effects on consumers' welfare, highlighting the danger that "The merger will place about $70 \%$ of wireless subscribers,...., in the hands of the Bell Operating Companies who,...., possess a monopoly in local wireline communications". The study predicts that, as a result of the merger, there will be higher wireless prices. More interestingly, by exploring the role played by the cross price elasticities between wireless and fixed access, it concludes that, by facilitating the internalization of the demand substitution effects, the merger will also raise fixed prices. In this paper we focus on the role played by cross price substitution between wireless and fixed access to the Internet in determining the incentives and the welfare effects of the merger studied.

The economic analysis of antitrust cases often focuses on the differences in terms of anti-competitive effects between vertical and horizontal mergers. A vertical merger between an essential input supplier and a firm operating in the downstream market is often feared for its threat of inducing partial or total foreclosure of downstream rivals. Ordover et al. (1990) studied the economic incentives for a vertical merger between a (nonmonopolist) seller of an upstream input and a retailer of the final good. In this scenario, the new vertically integrated firm is likely to foreclose the access to its production input to the 
non-merged downstream firms. ${ }^{2}$ Foreclosure due to the vertical merger makes the production input market less competitive since the downstream division of the integrated firm will benefit from the input cost differential. In a similar setting, Salinger (1988) maintained that, on the contrary, greater levels of vertical integration lead to decreasing input prices, and the final good's price will be lower than under non-integration.

Rey and Tirole (forthcoming) showed how the presence of asymmetric information leads an upstream monopolist to behave à la Cournot when supplying its essential input to downstream retailers. In this setting foreclosure represents an opportunity to re-establish monopoly profits, previously lost to asymmetric information. Rey and Tirole also prove that the incentives towards vertical foreclosure are inversely related to product differentiation in the downstream market and, interestingly, depend on the specific network location of the "bottleneck" generating monopoly power.

The richness of the notion of network, however, extends far beyond the usually analysed differences between the strategic effects of vertical and horizontal mergers and foreclosure. For example, Weisman (2003) suggests that antitrust guidelines place undue weight on market concentration, particularly in network industries. He shows that, with multi-market participation firms competing à la Cournot, if the different markets have complementary demands, a merger increasing both market concentration and the market share of multi-market participation firms can reduce prices independently of merger economies. Higgins (1997) also explores network relations to introduce the concept of a diagonal merger as one between an upstream firm, supplying a production input, and a retailer, not located in the immediate downstream market but supplying a substitute commodity of the one traded in the downstream market. ${ }^{3}$

In this paper, we analyse merger and foreclosure incentives and their welfare consequences in a setting where the merger is neither exclusively horizontal nor vertical ${ }^{4}$ but, given the network relations, it will be a mixture of the two. Because of the combined effects of these two dimensions, and borrowing Higgin's terminology but not its definition, we call this a diagonal merger.

In particular, we use Giovannetti's (2002) mixed hierarchy architecture to study the incentives towards merger and foreclosure for Internet access and transit providers simultaneously facing horizontal competition and a vertical production relationship. This kind of diagonal architecture is meant to capture the non-dedicated connectivity structure of Internet traffic flows and the multiplicity of Internet access modalities. In particular, we analyse the effects of horizontal competition between fixed and wireless providers in the Internet retail access.

\footnotetext{
${ }^{2}$ Such a result is strictly connected to the integrated firm not competing with other top-level firms. Reiffen (1992) underlines this condition stressing that vertical integration is neither necessary nor sufficient to have higher prices for intermediate goods.

${ }^{3}$ The author gives an example of what he defines as a diagonal merger: zinc is a brass input and brass is, in turn, a substitute for steel. As regards zinc, a monopoly seller is constrained in raising prices, since its products can be replaced by producers, and consumers might replace their use of brass for steel. In such a context, a merger between a zinc and a steel producer is neither horizontal (the two products are not direct substitutes) nor vertical (they are not tied to the same production process). This merger is therefore defined as a diagonal merger, and may produce potential anti-competitive effects. In fact, with such a merger between a zinc producer and a steel seller, the zinc monopolist could internalize some of the steel producer's advantages, caused by the rise in the brass price. Zinc's final price could thus be higher, because of the diagonal merger, and the less competitive the market for zinc, the stronger the negative impact on final consumers.

${ }^{4}$ For an introduction to the issue of vertical control see for example Chapter 4 of Tirole (1998).
} 
Our scheme is consistent with recent data which show the relevance of the retail wireless market: in February 2004 the GSM (Global System for Mobile communications), accounting for the $72 \%$ of the world's wireless market, reached one billion subscribers worldwide. ${ }^{5}$ By June 2004, in the U.S. alone, there were more than 170 million wireless subscribers. These numbers are particularly relevant for the potential of wireless Internet access which is becoming increasingly available through cards and/or mobile devices, capable of automatically switching between the best available Internet access modalities, such as GPRS, (General Packet Radio Service), UMTS (Universal Mobile Telecommunications Systems) and WiFi (Wireless Fidelity). The main feature of these new wireless standards is the increased differentiation they introduce, with respect to fixed Internet access, because of their portability and operability. The capacity of wireless access is likewise improving dramatically also in relation to the fixed access increments, as shown in Figure 1 below.

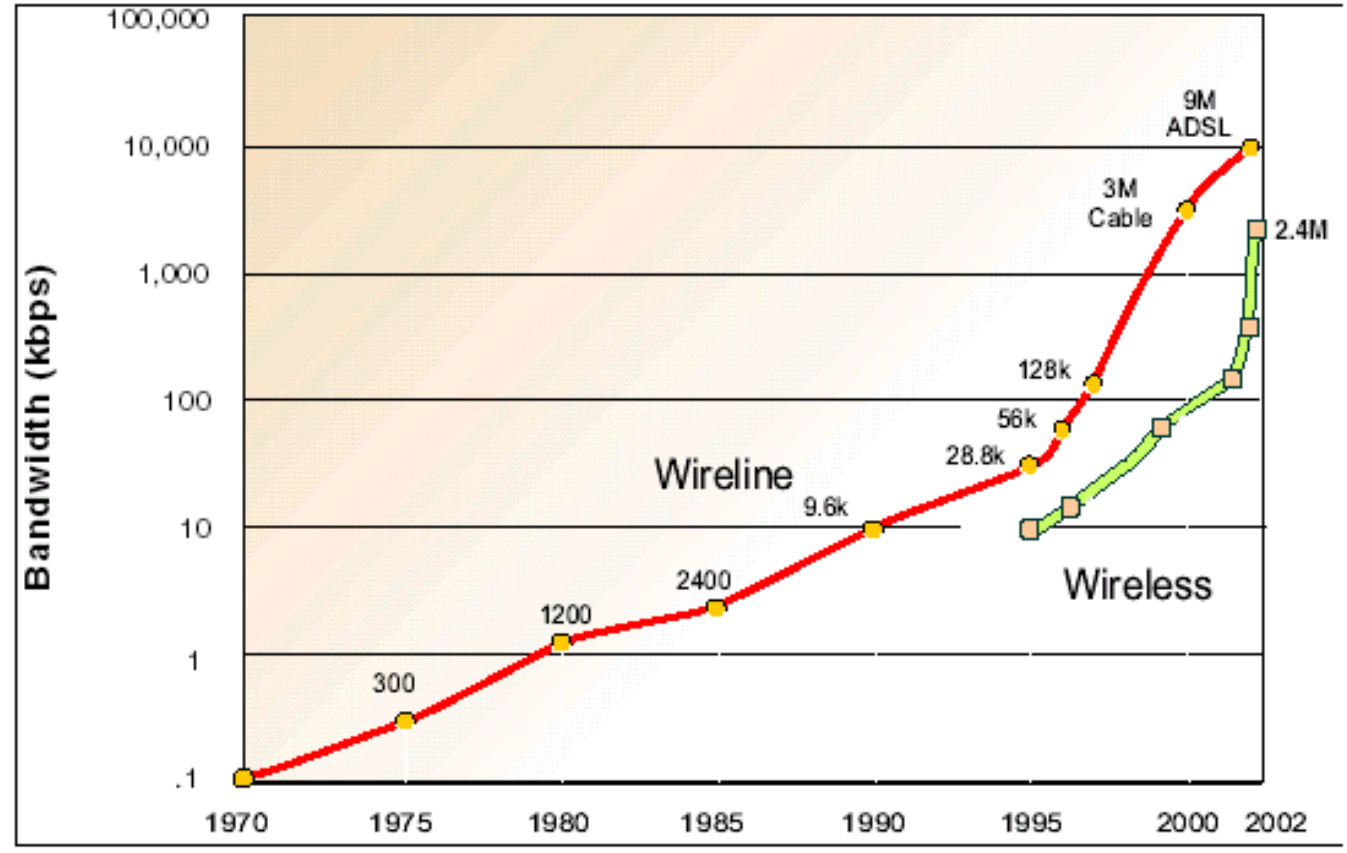

Figure 1: Wireline and wireless data rate growth

Source: Qualcomm

The results of this paper emphasize the relevance of the degree of product differentiation between wireless and fixed Internet access; product differentiation is derived from the preferences for variety of the final users ${ }^{6}$ who can mix different forms of

\footnotetext{
${ }^{5}$ Source GSM world media www.gsmworld.com

${ }^{6}$ The exact relation with the utility function is specified in the model below. However the main factor is that the competitiveness of the market due to product differentiation, is derived from the consumers' willingness to mix different forms of access and from the problems arising in doing so. We could think about mixing costs instead than switching costs. A similar approach can be seen in Waterson (2003).
} 
access, as happens for the fixed-wireless mix choice. Preferences for variety are likely to be affected by the appearance of new access standards in terms of extended portability. ${ }^{7}$

The early literature on Internet pricing considered the cost and benefits of different network pricing structures by focusing on the problem of congestion. One of the issues discussed was whether prices should be charged only at the retail level, the network edges, or at each network node, Shenker et al. (1996). ${ }^{8}$ Concerning the price paid by the final users for communicating, presumably downloading, we assume that information packets are priced at each router along their path. Following this motorway toll metaphor, the final user will pay a price given by the sum of router prices along the end-to-end download link. By assuming per packet pricing at each network node we also aim at capturing some relevant characteristics of the business model underlying wireless connectivity. For example a GPRS networks breaks down the information into packets and the operator needs to count packets to charge customers for the volumes they send and receive. ${ }^{9}$

The main findings of this paper are that the incentives to merge only arise if the Internet retail access modalities are either very differentiated, or if there is not too much differentiation. Also, with low differentiation, the excluded firm may gain from the merger of the other two. This suggests that the vertical merger of a direct retail competitor may indeed provide a collusive device to the industry as a whole when profits are eroded by low differentiation. As a consequence of the merger, and with very low product differentiation, the new equilibrium price structure induces foreclosure of the retail activity of one of the merged providers. However, this happens only in the market where the merger is horizontal. This same merged retail provider retains a positive demand in the other market where the merger was vertical.

The remainder of the paper is organized as follows: in section 2 we describe the model and the effects of product differentiation on equilibrium prices and profits. Section 3 contains the main results of the paper: in it we analyse the effects of the merger on prices, profits and market structure and we discuss its impact on foreclosure. Finally section 4 contains the conclusions of the paper. All the proofs are contained in the Appendix 1. Appendix 2 shows the timeline of 3rd generation mobile telephony by country and operator.

\section{The model}

Consider a stylized representation of the Internet, a network of networks, as a system describing the routing of two different one-way traffic flows: one connecting an originating location, $B_{1}$ to a terminating one, $B_{2}$ and the other connecting two equally vertically ordered flows originating in $A_{1}$ and terminating in $A_{2}$. Each traffic flow passes through two network nodes, the first being the origination and the second the termination one. Traffic flows can be seen as downloads from web-sites requested by final users. We

\footnotetext{
${ }^{7}$ Extending the compatibility between access to an I.P. network and existing devices such as mobile phones, PDA or even wrist-watches will indeed offer more variety and an increased willingness to combine sources of access.

${ }^{8}$ For a collection of material on Internet congestion pricing see for example, http://networks.ecse.rpi.edu/ yuksem/internet-pricing/literature/pricing_papers.html .

${ }^{9}$ The GSM association believes that it may well be the case that the cost of measuring packets is greater than their value, however decisions on charging for GPRS by packet or simply a flat monthly fee need to be made. http://www.gsmworld.com/
} 
assume that both originating locations, $B_{1}$ and $A_{l}$ have a retail market for access with two independent and competitive providers. This competition is modelled as taking place between wired and wireless access providers. Following this scheme, graphically reported in Figure 2 below, Internet Access, or origination, in $B_{1}$ can take place through ISP one which provides wireless access and through ISP three which provides fixed access. The same ISP one provides wireless access for origination in $A_{l}$ where it competes against a different fixed access provider, ISP two. Finally the terminating locations have a different market structure: $B_{2}$ has a single monopolistic local provider, ISP two, while in $A_{2} I S P$ three terminates the information flows originated from $A_{1}$ by the wireless access operator ISP one, while ISP two terminates the flows originated in $A_{1}$ by its own retail division.

Given this network architecture ISP one and three are both competing horizontally for the origination of traffic in $B_{1}$ and they face an upstream monopolist for termination in $B_{2}$; $I S P$ one and two are competing horizontally for the origination of the traffic in $A_{1}$ after which ISP one can only terminate traffic at $A_{2}$ through ISP three, while ISP two terminates its traffic through its upstream division only. ISP two terminates the traffic from external retailers only for flows originated at locations where it is not a retailer itself.

Figure 2 below describes the possible information transfers and the ownership structure of these interacting markets.

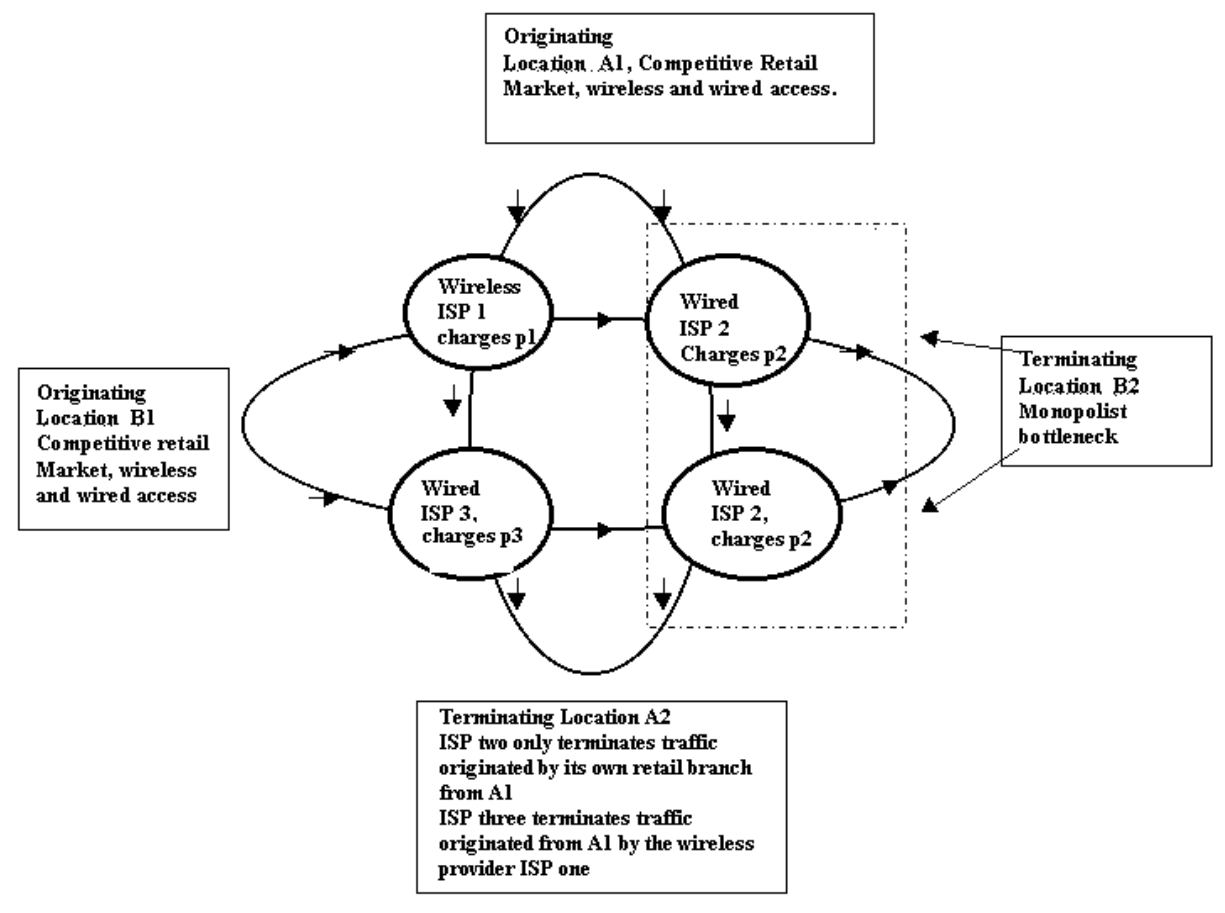

Figure 2: Pre-merger market structure

The larger dotted box in Figure 2 shows nodes ownership and ISP two's monopoly power over termination in $B_{2}$.

The request for downloads originating in $\mathrm{B}_{1}$ and terminating in $B_{2}$ is given by

(1) $x^{B}=x_{1}{ }^{B}+x_{3}{ }^{B}$ 
where $x_{1}{ }^{B}$ is the packet rate going through ISP one, with wireless access, and $x_{3}{ }^{B}$ is the packet rate going through ISP three, the fixed access one.

Similarly the request for downloads originated in $\mathrm{A}_{1}$ and terminated in $\mathrm{A}_{2}$ is given by

(2) $x^{A}=x_{1}{ }^{A}+x_{2}{ }^{A}$

We also assume that due to technological or regulatory reasons, no ISP is able to price discriminate between packets originating either in $A_{l}$, or in $B_{l}$ and therefore just charges the same node price whenever information packets are transmitted across its routers.

\subsection{Demand for Internet access}

We assume the following utility function ${ }^{10}$ for the $B_{1}$ originating market

$$
U_{B}=\left[\alpha\left(x_{1}+x_{3}\right)-\left(\frac{1}{2}\left(x_{1}^{2}+x_{3}^{2}\right)\right)-\gamma\left(x_{1} x_{3}\right)\right]+m
$$

and similarly for $A_{1}$

(4) $U_{A}=\left[\alpha\left(x_{1}+x_{2}\right)-\left(\frac{1}{2}\left(x_{1}^{2}+x_{2}^{2}\right)\right)-\gamma\left(x_{1} x_{2}\right)\right]+m$

From (3) and (4), it is easy to derive the linear demand functions for retail Internet Access through the wireless provider, ISP one, and through the fixed one, ISP three originating in $\mathrm{B}_{1}$ :

$$
\begin{aligned}
& \text { (5) } x_{1}{ }^{B}=\frac{\alpha}{1+\gamma}-\frac{1}{1-\gamma^{2}}\left(p_{1}+p_{2}\right)+\frac{\gamma}{1-\gamma^{2}}\left(p_{3}+p_{2}\right) \\
& \text { (6) } x_{3}{ }^{B}=\frac{\alpha}{1+\gamma}-\frac{1}{1-\gamma^{2}}\left(p_{3}+p_{2}\right)+\frac{\gamma}{1-\gamma^{2}}\left(p_{1}+p_{2}\right)
\end{aligned}
$$

where $\left(p_{1}+p_{2}\right)$ is the retail price for accessing the net through the wireless ISP one and terminating it through ISP two and $\left(p_{3}+p_{2}\right)$ the retail price to pay for access through the fixed ISP three and again terminating it through ISP two, the $\mathrm{B}_{2}$ 's termination monopolist.

Similarly for the traffic originating in $\mathrm{A}_{1}$ we have:

\footnotetext{
${ }^{10}$ The first term of the nonlinear part of the equation expresses the utility for the total sending rate weighted by the parameter $\alpha$ linked to the size of the market. The second term, describes the consumers willingness to mix between different sources of access: fixed and wireless. This has an immediate interpretation: suppose we can access the network via a fixed connection or via a UMTS wireless connection; this variety of access modes allows the use of the most convenient connection at each moment. The third term of the utility function accounts for the disutility derived from having two different providers. This dis-utility from variety expresses the opportunity costs for the time spent reading different contracts and bills, paying them separately, accessing two different support numbers for any query, learning different aspects of the connection and so on, the mixing costs. The parameter $\gamma$, describes the trade off between the desire for variety and the effort to minimize mixing costs due to multi-homing. When $\gamma$ tends to one there is no preference for variety: the mixing costs associated with having two different providers exactly offset the benefits derived from variety. Finally $m$, the linear part of the utility functions (3) and (4) represents a composite, non-Internet related, commodity.
} 
(7) $x_{1}{ }^{A}=\frac{\alpha}{1+\gamma}-\frac{1}{1-\gamma^{2}}\left(p_{1}+p_{3}\right)+\frac{\gamma}{1-\gamma^{2}}\left(2 p_{2}\right)$

(8) $x_{2}{ }^{A}=\frac{\alpha}{1+\gamma}-\frac{1}{1-\gamma^{2}}\left(2 p_{2}\right)+\frac{\gamma}{1-\gamma^{2}}\left(p_{1}+p_{3}\right)$

From the demand functions we can see that the coefficient $a=\frac{\alpha}{1+\gamma}$ represents the positive effects of market size through the parameter $\alpha$ of the original quasi-linear utility function; the coefficient $b=\frac{1}{1-\gamma^{2}}$ expresses the negative relation between own price and demand, the own price effect, while $c=\frac{\gamma}{1-\gamma^{2}}$ describes the positive demand effect of a rise in the competitor's price, the cross price effect. The ratio of these two effects, $\frac{c}{b}$, describes the degree of competitiveness in the retail sector, when $\frac{c}{b}=0$, there is no competition, while when $\frac{c}{b}=1$ there is perfect substitution between the two access modalities and full competition. Moreover clearly the competitiveness ratio equals the parameter of the mixing costs in the original quasi-linear utility function: $\frac{c}{b}=\gamma$.

When $\gamma$ equals zero, consumers like variety of access modalities, there is no competition, because of a zero cross price effect and each provider has a safe market niche; when $\gamma$ tends to one, consumer dislike variety and the industry becomes perfectly competitive, since cross and own price effect tend to coincide. The consumers' dislike for variety, expressed by the parameter $\gamma$, is therefore inversely related to the level of differentiation in Internet access modalities.

In the following game, each provider sets its prices, simultaneously, the variable cost of routing a rate $x_{i}$ is zero at each network node and the fixed cost is zero, or sunk.

\subsection{Equilibrium prices and profits}

The next proposition studies the effects of product differentiation on equilibrium prices, wireless and fixed, market shares and profits for the model introduced above ${ }^{11}$

\section{Proposition 1:}

a) The wireless price charged by ISP one, $p_{1}$, and the price charged by the fixed ISP three, $p_{3}$, are equal and both increasing in differentiation; the price charged by the fixed ISP two, $p_{2}$, is always lower than the other two prices and is also increasing in differentiation.

\footnotetext{
${ }^{11}$ This network architecture has been introduced by Giovannetti (2002), we consider however a different model based on the motorway toll assumption that the prices to cross each node are paid for at the node and they enter into the retail consumer price. Moreover this proposition is mainly used as a benchmark against the following analysis of the merger case, which was not present in Giovannetti.
} 
b) In the originating market $A_{1}$ where the wireless provider competes against a vertically integrated fixed provider, the wireless market share:

(9) $\frac{x_{1}^{A}}{x_{1}^{A}+x_{2}{ }^{A}}$

Is smaller than that of the fixed one and is decreasing in product differentiation

a) All providers' profits are decreasing in $\gamma$ and they tend to zero as $\gamma \rightarrow 1$.

Proof: See Appendix

Discussion: Although this proposition is mainly used for comparison purposes, it is of interest on its own. The motor-way toll pricing structure used removes some of the vertical relations between providers: there is indeed no access price paid by the providers to each other. However it is interesting to notice that in the originating market $A_{l}$, where the competition is between the vertically integrated ISP two and the non-vertically integrated wireless ISP one, we observe asymmetric market shares. Moreover given the decreasing relation between wireless market share and product differentiation we find a complementarity between market power, due to vertical integration, and consumers' preferences for variety. Vertical integration matters the most when there is high differentiation, with lower differentiation the advantage of the vertically integrated competitor vanishes in the limit.

\section{$3 \quad$ Merger}

In this section, we consider the incentives for, and the consequences of, a merger between the fixed ISP two and the wireless ISP one. We focus on the effects of this merger on equilibrium prices, profits and resulting market structure including the possibility of endogenous foreclosure. Again these effects will depend on the degree of differentiation in the retail sector for Internet access.

\subsection{New market structure}

Assume that the wireless ISP one and the fixed ISP two have now merged. As a consequence in market $\mathrm{A}_{1}$ the same ISP will set both prices: the wireless $p_{1}$ and the fixed one, $p_{2}$. This merger is, at the same time, an horizontal merger for market $\mathrm{A}_{1}$ where the retail market is now controlled by one ISP and a vertical merger for the retail market in $B_{1}$. With respect to the traffic originated in $B_{I}$ the wireless provider, ISP one, is now vertically integrated with the upstream provider, ISP two, see figure 3 below.

These combined effects of the merger on the network topology imply that the merger is neither only horizontal nor only vertical, we define it diagonal. 


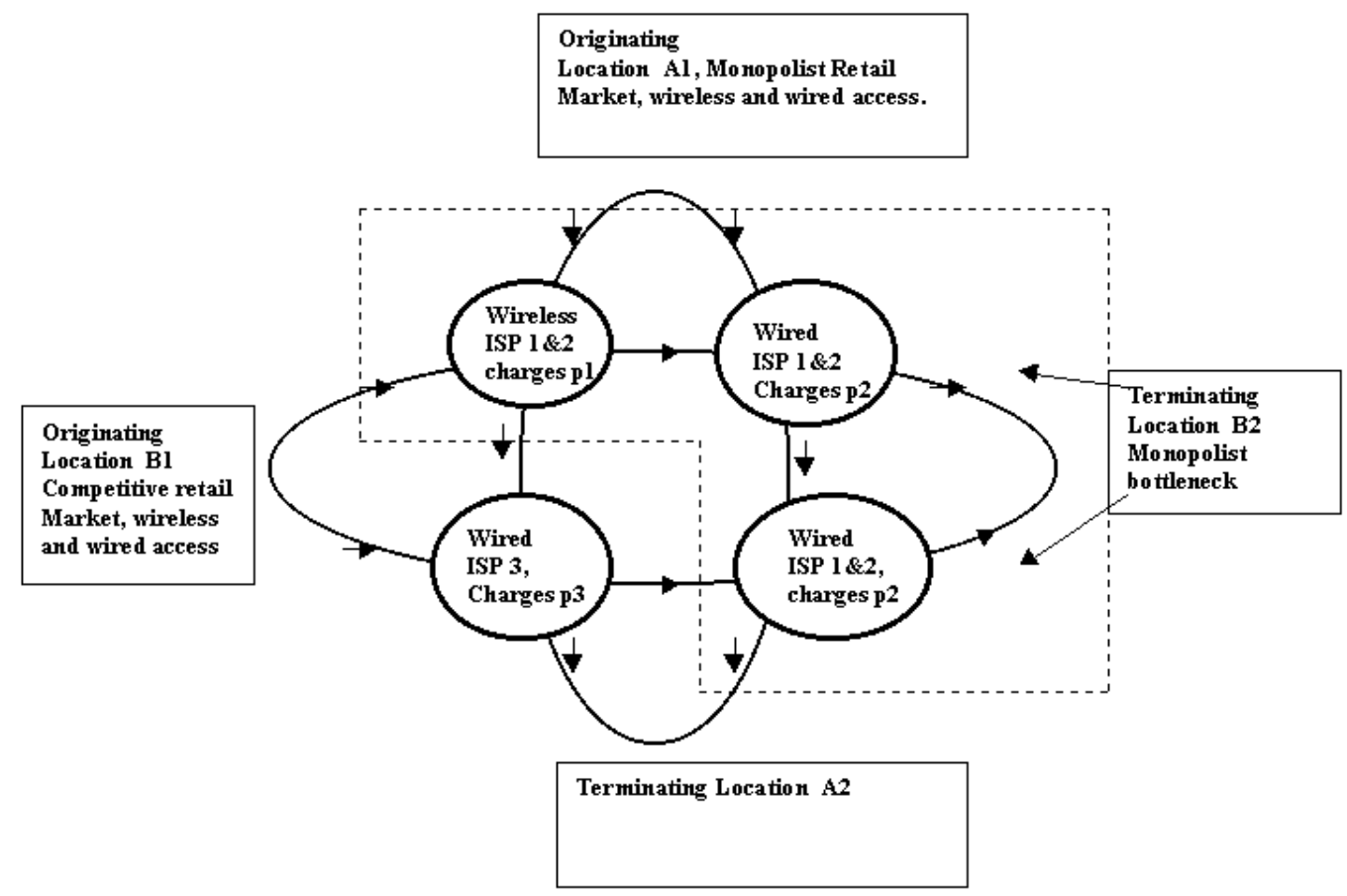

Figure 3: Post-merger market structure

In the next proposition, we study the effects of the merger on the industry. These will be more relevant for the market where the merger is vertical, $B_{1}$, indeed with low differentiation, the merger will imply the foreclosure of the retail market for the wireless provider in $B_{l}$.

\section{Proposition 2}

a) There is a critical value of the mixing cost parameter, $\gamma$, such that for very low differentiation the wireless retail access in the originating location $B_{1}$ is price foreclosed: if $\gamma \geq 0.965 \rightarrow x_{1}^{B}=0$.

b) With high differentiation we have that the non merged ISP three will have higher retail prices than the others: if $\gamma \leq 0.34 \rightarrow p_{3}>p_{1}>p_{2}$

c) For intermediate values of differentiation the highest price is the wireless one charged by the newly merged ISP $1 \& 2$ : if $0.34 \leq \gamma \leq 0.55 \rightarrow p_{1}>p_{3}>p_{2}$

d) For even lower differentiation while the wireless access price remains the highest, the non merged ISP three will be charging the lowest retail price: if $\gamma \geq 0.55 \rightarrow p_{1}>p_{2}>p_{3}$.

Proof: See Appendix. 
Discussion: This proposition deals with the effects of the merger on the node prices. Part a) finds a foreclosure value for $\gamma$ : for very $\operatorname{low}^{12}$ differentiation levels the wireless price level is high enough to make the demand on the $\mathrm{B}_{1}$ market for wireless access go to zero. The same price level is, however, low enough to maintain positive wireless demand on the originating $A_{1}$ market. The strongest qualitative implication of the merger concerns therefore the market where the merger is vertical and horizontal competition is still possible. This is clearly due to the new monopoly power acquired on the originating market $A_{1}$ by the merged firm, explaining its benefits in charging a high price even at the cost of losing the wireless market in B1.

The next proposition focuses on the effects of the merger on the wireless market shares, and on prices in comparison with the pre-merger case.

\section{Proposition 3}

a) As a consequence of the merger the wireless market share in the $B_{1}$ originating market, is increased for high differentiation, if $\gamma \leq 0.34$.

b) The wireless market share in the $A_{l}$ market decreases, after the merger only for intermediate values of the differentiation parameter, if $0.34 \leq \gamma \leq 0.55$.

c) Furthermore the merger will imply: a reduction the retail price of the wireless price, $p_{1}$, for $\gamma \leq 0.34$,

d) a reduction of the price of the fixed access, $p_{2}$, again for $\gamma \leq 0.34$ and

e) a reduction of the price of the fixed, and independent, provider ISP three, $p_{3}$ for intermediate values of the differentiation parameter: $0.33 \leq \gamma \leq 0.59$.

Proof: See the Appendix.

Discussion: This proposition shows again the interaction between differentiation and merger effects. For a highly differentiated industry the merger implies a higher wireless market share than in the pre-merger case in both markets. The effects of differentiation on the market where the merger is horizontal is however nonlinear. Indeed both a low and a high, but not an intermediate, differentiation levels imply an increase of the wireless market share in this market. Finally the merger will increase all prices if there is low differentiation while it will only reduce the price of the excluded ISP and raising the others if there is an intermediate level of differentiation, and reduce the merged ones while raising the excluded for high differentiation.

\subsection{The incentives for mergers}

After having studied the consequences of a merger between the wireless ISP one and the fixed ISP two we are now ready to analyse the incentives for these ISPs to merge and the profit impact of the merger on the third provider. In the next proposition we will see that there is a parameter range for which the merger can be profitable for all the providers, even for ISP three, excluded from the merger.

\footnotetext{
${ }^{12}$ High mixing costs, $\gamma$.
} 


\section{Proposition 4}

a) ISP one and two have no incentive to merge only for a limited range of highintermediate differentiation levels: if $0.16 \leq \gamma \leq 0.32$

b) ISP three will loose profits from the merger, between ISP one and ISP two, for an intermediate differentiation level, where it is profitable for the other two to merge, if $0.33 \leq \gamma \leq 0.58$.

Proof: See the Appendix.

Discussion: Clearly again the economic incentives for the merger depend on the degree of differentiation in the retail market for Internet access. The merged firm gains from it if the industry is either very differentiated or if there is not too much differentiation. In a subset of this last, low differentiation, interval also the excluded firm gains from the merger of the other two. This suggests that the vertical merger of a direct retail competitor may indeed provide a collusive device to the industry as a whole when profits are eroded by low differentiation.

Finally the next proposition explores the wider welfare effects of the merger on the consumers of the separate markets, and on them as a whole.

Proposition 5: The merger:

a) increases consumers' surplus in the $B_{l}$ market for high differentiation: if $\gamma \leq 0.318$

b) increases consumers' surplus in the $A_{l}$ market, also for high differentiation: if $\gamma \leq$ 0.335 .

c) increases total consumer's surplus if $\gamma \leq 0.325$

d) decreases total profits if $0.33 \leq \gamma \leq 0.43$, and

e) increases total welfare if $\gamma \leq 0.325$.

Proof: See the Appendix.

Discussion: In the figure 4 below we plot the consumers' surplus changes due to the merger, the solid line is for the $A_{1}$ market and the dotted line for the $B_{1}$ market. From the graph we can see that on the $B_{l}$ market where the merger was vertical we have less intense effects than in the $A_{l}$ market, both when they are positive, with high differentiation and when they are negative, with low differentiation. 


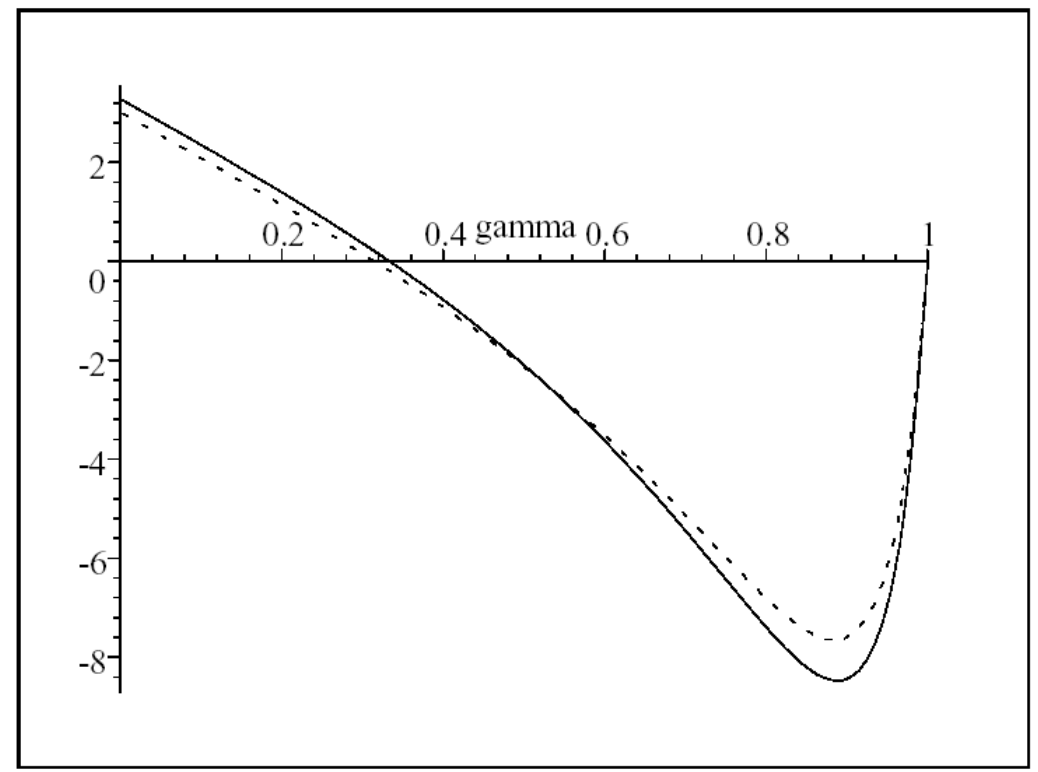

Figure 4: Consumer's welfare effects of the merger

\section{Conclusions}

Competition policy usually focuses either on the potential collusive use of access prices, in the case of horizontal networks, or on discriminatory policies on access conditions in the case of networks with a vertical hierarchy. Both the EU New Interconnection Directive ${ }^{13}$ and the WTO Reference Paper, binding for over 60 member States, provide for nondiscriminatory and cost-based arrangements for network interconnection and access fees. In any case, this regulatory framework only targets the operators in a dominant position, often arising from the presence of a termination bottleneck, as modelled in our stylized network.

The Internet developed without a dedicated regulatory framework ${ }^{14}$, whose implementation would be particularly complicated due to its trans-national nature. However the potential impact of vertical and/or horizontal mergers in the Internet have been scrutinized during antitrust inquiries conducted by the Department of Justice of the U.S. and by the European Commission ${ }^{15}$ leading to the prohibition or the (conditional) authorization of mergers between large backbones, such as the ones between MCI and Worldcom and between MCI-Worldcom and Sprint. These inquiries showed the limitations of the different approaches ${ }^{16}$ used to estimate market concentration in the

\footnotetext{
${ }^{13}$ See Official Journal Of the European Commission (2002).

${ }^{14}$ For a seminal contribution see Kende (2000).

${ }^{15}$ For the original documents: Official Journal Of the European Commission (2000) and U.S. Department of Justice (2000).

${ }^{16}$ For example revenue based estimates present serious problems due to the mixing of revenue data from different Internet segments, and are particularly misleading for vertically integrated backbones. Traffic based market share measurements are particularly difficult to obtain given the proprietary structure of the
} 
Internet Backbone and pointed to the necessity of using game theoretic analysis for assessing the outcomes of strategic interaction in network environments. Again, our stylised network captures some specific aspects of these interrelations: firms route traffic arising from different origination markets, and with different termination ones, through the same nodes charging a unique node price. Moreover, network interactions may provide specific forms of cross market influence: a firm that dominates one market, for instance, may offer very high prices to subsidise lower prices in the more competitive markets in which it operates ${ }^{17}$, or a network merger may imply forms of price or non price foreclosure. ${ }^{18}$ We have been specifically dealing with the effects of a network merger on price foreclosure focussing on the specific network architectural features providing the incentives for foreclosure.

We also focussed on the role played by consumers' preferences for variety in the modalities of Internet access. These are clearly affected by the type of access technologies competing on the retail market. The recent appearance of UMTS in many markets will, for example, surely influence these preferences that, as we have seen, define the competitiveness of the retail markets and determine both the final market structure and the welfare consequences of a network merger.

In detail, we considered two interconnected competitive retail originating markets both providing fixed and wireless access to the Internet, and two termination markets, one of them monopolized by a single ISP, a bottleneck also vertically integrated with one of the retailers in one of the originating markets. Destination markets can be thought as webhosting sites, so that the model demand functions refer to download requests.

Before the merger takes place, equilibrium prices and providers profits crucially depend on the degree of differentiation in the retail industry. The more consumers appreciate the variety of the access services the more the retail market is differentiated, the higher are the node prices and the smaller the market share for the wireless operator in the market where it competes against the vertically integrated fixed access provider. This result is interesting because it links preferences for variety to market structure, when a retail provider is competing against a vertically integrated one, which is also its upstream provider for a different market. We then considered a merger in one of the retail markets, between the vertically integrated fixed access provider and the wireless one. This merger is horizontal for one of the markets but vertical for the other, it has therefore original effects typical of the connection-less structure of an I.P. network such as the Internet. The effects of the merger again depend on the degree of differentiation introduced by the wireless access. For very low differentiation the merger implies a partial price foreclosure for the wireless activity of the merged provider. Partial since the wireless price induces a zero demand in the market where the merger is vertical, maintaining however a positive demand for wireless access in the other market, where the merger is horizontal. Post merger prices are lower than pre-merger ones if there is low differentiation, they are higher otherwise. Consumer welfare diminishes as a result of the merger if there is not enough

backbones. Routing techniques for the estimate of backbone market shares are based on an annual survey counting the upstream interconnections of ISPs carried by Boardwatch but have been criticized for not considering the individual relevance of these connections. Finally a network architecture based approach, as used by Telegeography, considers International Internet Connectivity solely on deployed and operational bandwidth. See Abramson (2001) and Giovannetti and Ristuccia (2004).

${ }^{17}$ The WTO Reference Paper specifically prohibits such a practice, which is highly anti-competitive and the EU New Interconnection Directive is attributing greater power to the NRA to detect it.

${ }^{18}$ See the literature discussed in the introduction of this paper. 
differentiation, while industry profits will usually increase, apart for an intermediate differentiation parameter range, where they decrease.

Antitrust authorities should carefully scrutinize both the network design-relations and the technological conditions of the providers involved in a merger in order to fully assess its likely consequences. We have seen, by combining propositions 4 and 5, that with high differentiation, we have the incentives for a merger with positive consumers' welfare effects, while with low differentiation the incentives for the merger are again positive but the welfare consequences are negative. The degree of differentiation between merger candidates, by affecting the consumers' preference for variety, and eventually the equilibrium properties of the emerging market structure, should always be assessed.

\section{$5 \quad$ References}

Abramson, B.D. (2001) "Interpreting Current Statistics: Internet Backbone Market Shares," Telecom Reform, 1: 1-14.

Armstrong, M. (2002) "The Theory of Access Pricing and Interconnection," in M. Cave, S.K. Majumdar, \& I. Vogelsang (ed.) Handbook of Telecommunications Economics. Amsterdam: Elsevier.

Buccirossi, P. (1999) “Access to an Essential Facility: Efficient Component Pricing Rule or Unrestricted Private Property Rights?” Journal of Regulatory Economics, 16: 287-296.

Center, P. (2004) "Higher Prices Expected from the Cingular/AT\&T Wireless Merger," Phoenix Center Policy Bulletin, 11. http://ssrn.com/abstract=552701

Crèmer, J., J.P. Rey, and J. Tirole (2000) "Connectivity in the Commercial Internet," Journal of Industrial Economics, 48: 433-472.

Doyle, G. (2002) Media Ownership. London: Sage Publications.

Foros, Ø., and J. Hansen (2001) "Competition and Compatibility among Internet Service Providers," Information Economics and Policy, 13: 411-425.

Foros, Ø., H.J. Kind and L. Sørgard (2004) "Strategic Regulation Policy in the Internet," Working paper 31/04 SNF.

Giovannetti, E. (2002) "Interconnection, Differentiation and Bottlenecks in the Internet," Information Economics and Policy, 14: 385-404.

Giovannetti, E. and C. A. Ristuccia (2005) "Estimating Market Power in the Internet backbone using the I.P. transit Band-X Database," Telecommunications Policy, forthcoming.

Goyal, S. and S. Joshi (2003) "Networks of Collaboration in Oligopoly," Games and Economic Behavior, 43: 57-85. 
Higgins R. S. (1997) “Diagonal Merger,” Review of Industrial Organization, 12: 607-623.

Kende, M. (2000) “The Digital Handshake: Connecting Internet Backbones," Federal Communications Commission OPP Working Paper No. 32

Laffont, J.-J. and J. Tirole (2000) Competition in Telecommunications. Cambridge, Massachusetts: MIT Press.

Laffont, J. -J., S. Marcus, P. Rey and J. Tirole (2003) "Internet Interconnection and the Off-Net-Cost Pricing Principle," RAND Journal of Economics, 34: 370-90.

Official Journal Of the European Commission (2000) Regulation (EEC) N 4046/89, Merger Procedure, Brussels, European Commission, DGXIII.

Official Journal Of the European Commission (2002) "Access to, and Interconnection of, Electronic Communication Networks and Associated Facilities," Directive 2002/19/EC/.

Ordover, J.A., G. Saloner, and S.C. Salop (1990) "Equilibrium Vertical Foreclosure," American Economic Review, 80: 127-42.

Qualcomm The Economics of Wireless Mobile Data http://www.qualcomm.com/main/whitepapers/WirelessMobileData.pdf.

Reiffen, D. (1992) "Equilibrium Vertical Foreclosure: Comment," The American Economic Review, 82: 694-697.

Rey, P., and J. Tirole (forthcoming) "A Primer on Foreclosure," In M. Armstrong. \& R.H. Porter (ed.) Handbook of Industrial Organization, III. New York: North-Holland.

Shenker, S., D. Clark, D. Estrin, and S. Herzog (1996) "Pricing in Computer Networks: Reshaping the Research Agenda," Telecommunications Policy, 20: 183-201.

Salinger, M.A. (1988) "Vertical Mergers and Market Foreclosure," The Quarterly Journal of Economics, 103: 345-356.

Sidak, J.G. (2002) "Capital Subsidies, Profit Maximization, and Acquisitions by Partially Privatized Telecommunications Carriers," Telecommunications Policy, 26: 287-294.

Tirole, J (1988) The Theory of Industrial Organization. Cambridge, Massachusetts: MIT Press.

U.S. Department of Justice (2000) Civil Action against WorldCom Inc. and Sprint Corporation, June 26.

Waterson, M. (2003) "The Role of Consumers in Competition Policy," International Journal of Industrial Organization, 21: 129-150.

Waverman, L. and F. Trillas (2002) "Corporate Control and Industry Structure in Global Communications: An Introduction,” Telecommunications Policy, 26: 219-224 . 
Weisman, D. L. (2003) "A Generalized Pricing Rule for Multi-market Cournot Oligopoly," Economics Letters, 81: 95-99.

\section{$6 \quad$ Appendix 1}

\section{Proof of Proposition 1}

Demands are given by

(1)

$$
\begin{aligned}
& x_{1}{ }^{B}=\frac{\alpha}{1+\gamma}-\frac{1}{1-\gamma^{2}}\left(p_{1}+p_{2}\right)+\frac{\gamma}{1-\gamma^{2}}\left(p_{3}+p_{2}\right) \\
& x_{3}{ }^{B}=\frac{\alpha}{1+\gamma}-\frac{1}{1-\gamma^{2}}\left(p_{3}+p_{2}\right)+\frac{\gamma}{1-\gamma^{2}}\left(p_{1}+p_{2}\right) \\
& x_{1}{ }^{A}=\frac{\alpha}{1+\gamma}-\frac{1}{1-\gamma^{2}}\left(p_{1}+p_{3}\right)+\frac{\gamma}{1-\gamma^{2}}\left(2 p_{2}\right) \\
& x_{2}{ }^{A}=\frac{\alpha}{1+\gamma}-\frac{1}{1-\gamma^{2}}\left(2 p_{2}\right)+\frac{\gamma}{1-\gamma^{2}}\left(p_{1}+p_{3}\right)
\end{aligned}
$$

To construct best reply functions we need to consider the possibility that an ISP sets prices as to "close" one market. This is relevant since firms now play with one price on two different markets and we need to verify if corner solutions are best replies. In the following we set up the Lagrangeans for the three firms and we find that the internal solutions form equilibrium for the game

\section{ISP one}

Imposing the non-negativity constraints for the two final demands routed by ISP one, we have the Lagrangean function:

(2)

$$
\begin{aligned}
& L_{1}=\left[\frac{\alpha}{1+\gamma}-\frac{1}{1-\gamma^{2}}\left(p_{1}+p_{2}\right)+\frac{\gamma}{1-\gamma^{2}}\left(p_{3}+p_{2}\right)+\frac{\alpha}{1+\gamma}-\frac{1}{1-\gamma^{2}}\left(p_{1}+p_{3}\right)+\frac{\gamma}{1-\gamma^{2}}\left(2 p_{2}\right)\right] p_{1}+ \\
& \mu_{1}\left(\frac{\alpha}{1+\gamma}-\frac{1}{1-\gamma^{2}}\left(p_{1}+p_{2}\right)+\frac{\gamma}{1-\gamma^{2}}\left(p_{3}+p_{2}\right)\right)+\mu_{3}\left(\frac{\alpha}{1+\gamma}-\frac{1}{1-\gamma^{2}}\left(p_{1}+p_{3}\right)+\frac{\gamma}{1-\gamma^{2}}\left(2 p_{2}\right)\right)
\end{aligned}
$$

from which we can derive the reaction function for ISP one: 
(3)

$$
\begin{aligned}
& -\gamma \alpha+p_{3} \gamma+\gamma p_{2}+\alpha-p_{2} \quad \text { if } \quad p_{3} \leq \frac{p_{1}+\gamma \alpha-\gamma p_{2}-\alpha+p_{2}}{\gamma} \\
& p_{1}=\left\{- \frac { 1 } { 2 } \gamma \alpha + \frac { 1 } { 4 } p _ { 3 } \gamma + \frac { 3 } { 4 } p _ { 2 } \gamma + \frac { 1 } { 2 } \alpha - \frac { 1 } { 4 } p _ { 2 } - \frac { 1 } { 4 } p _ { 3 } \quad \text { if } \left\{\begin{array}{l}
p_{2}>\frac{1}{2} \frac{\gamma \alpha-\alpha+p_{1}+p_{3}}{\gamma} \\
p_{3}>\frac{p_{1}+\gamma \alpha-\gamma p_{2}-\alpha+p_{2}}{\gamma}
\end{array}\right.\right. \\
& -\gamma \alpha+2 \gamma p_{2}+\alpha-p_{3} \\
& \text { if } \quad p_{2} \leq \frac{1}{2} \frac{\gamma \alpha-\alpha+p_{1}+p_{3}}{\gamma}
\end{aligned}
$$

\section{ISP two}

The Lagrangean for ISP two is given by

$$
\begin{gathered}
L_{2}=\left[\begin{array}{c}
\left.\left(\frac{\alpha}{1+\gamma}-\frac{1}{1-\gamma^{2}}\left(p_{1}+p_{2}\right)+\frac{\gamma}{1-\gamma^{2}}\left(p_{3}+p_{2}\right)\right)+\right] \\
\left(\frac{\alpha}{1+\gamma}-\frac{1}{1-\gamma^{2}}\left(p_{3}+p_{2}\right)+\frac{\gamma}{1-\gamma^{2}}\left(p_{1}+p_{2}\right)\right)
\end{array}\right] p_{2}+ \\
\lambda\left(\frac{\alpha}{1+\gamma}-\frac{1}{1-\gamma^{2}}\left(2 p_{2}\right)+\frac{\gamma}{1-\gamma^{2}}\left(p_{1}+p_{3}\right)\right)
\end{gathered}
$$

and its reaction function:

(5) $p_{2}=\left\{\begin{array}{ccc}-\frac{1}{2} \gamma \alpha+\frac{1}{2} p_{1} \gamma+\frac{1}{2} p_{3} \gamma+\frac{1}{2} \alpha & \text { if } & p_{1} \leq \frac{\gamma \alpha-p_{3} \gamma-\alpha+2 p_{2}}{\gamma} \\ -\frac{1}{4} \frac{3 p_{3} \gamma+3 p_{1} \gamma-4 \gamma \alpha-p_{1}-p_{3}+4 \alpha}{\gamma-3} & \text { if } & p_{1}>\frac{\gamma \alpha-p_{3} \gamma-\alpha+2 p_{2}}{\gamma}\end{array}\right.$

\section{ISP Three}

The Lagrangean is given by:

$$
\left.\begin{array}{l}
L_{3}=\left[\begin{array}{l}
\left(\frac{\alpha}{1+\gamma}-\frac{1}{1-\gamma^{2}}\left(p_{3}+p_{2}\right)+\frac{\gamma}{1-\gamma^{2}}\left(p_{1}+p_{2}\right)\right)+ \\
\left(\frac{\alpha}{1+\gamma}-\frac{1}{1-\gamma^{2}}\left(p_{1}+p_{3}\right)+\frac{\gamma}{1-\gamma^{2}}\left(2 p_{2}\right)\right)
\end{array}\right] p_{3}+ \\
+\varphi\left(\frac{\alpha}{1+\gamma}-\frac{1}{1-\gamma^{2}}\left(p_{3}+p_{2}\right)+\frac{\gamma}{1-\gamma^{2}}\left(p_{1}+p_{2}\right)\right)
\end{array}\right]
$$

and its reaction function: 
(7) $p_{3}=\left\{\begin{array}{ccr}-\gamma \alpha+p_{1} \gamma+p_{2} \gamma+\alpha-p_{2} & \text { if } & p_{1} \leq \frac{\gamma \alpha-p_{2} \gamma-\alpha+p_{3}+p_{2}}{\gamma} \\ -\frac{1}{2} \gamma \alpha+\frac{1}{4} p_{1} \gamma+\frac{3}{4} \gamma p_{2}+\frac{1}{2} \alpha-\frac{1}{4} p_{2}-\frac{1}{4} p_{1} & \text { if } & p_{1}>\frac{\gamma \alpha-p_{2} \gamma-\alpha+p_{3}+p_{2}}{\gamma}\end{array}\right.$

The internal solutions of the system of reaction functions (12), (14) and (16) are given by:

$$
\begin{aligned}
p_{1} & =2 \alpha \frac{\gamma^{2}+4 \gamma-5}{7 \gamma^{2}+10 \gamma-29} \\
\text { (8) } p_{2} & =4 \alpha \frac{\gamma^{2}+\gamma-2}{7 \gamma^{2}+10 \gamma-29} \\
p_{3} & =2 \alpha \frac{\gamma^{2}+4 \gamma-5}{7 \gamma^{2}+10 \gamma-29}
\end{aligned}
$$

Before concluding that these are equilibrium prices we need to check whether, at these prices, any constraint is binding. By substituting (17) into (10) we obtain the actual equilibrium demands.

$$
\begin{aligned}
x^{B}{ }_{1} & =\alpha \frac{\gamma^{2}-2 \gamma-11}{\left(7 \gamma^{2}+10 \gamma-29\right)(1+\gamma)} \\
x^{A}{ }_{1} & =\alpha \frac{-\gamma^{2}-2 \gamma-9}{\left(7 \gamma^{2}+10 \gamma-29\right)(1+\gamma)} \\
x^{A}{ }_{2} & =\alpha \frac{3 \gamma^{2}-2 \gamma-13}{\left(7 \gamma^{2}+10 \gamma-29\right)(1+\gamma)} \\
x^{B}{ }_{3} & =\alpha \frac{\gamma^{2}-2 \gamma-11}{\left(7 \gamma^{2}+10 \gamma-29\right)(1+\gamma)}
\end{aligned}
$$

which are always positive for all $\gamma \in(0,1)$

a) is easily derived from (17).

b) From (18) one obtains the wireless market share (9) for the asymmetric market A

$$
\frac{x_{1}{ }^{A}}{x_{1}{ }^{A}+x_{2}{ }^{A}}=-\frac{1}{2} \frac{\gamma^{2}+2 \gamma+9}{\gamma^{2}-2 \gamma-11}
$$

which is clearly increasing in $\gamma$.

\section{Equilibrium profits}

From (17) and (18) we obtain the equilibrium profits for the three operators 
(10)

$$
\begin{aligned}
& \pi_{1}=-8(\gamma+5)\left(\gamma^{2}+4 \gamma-5\right) \frac{\alpha^{2}}{(1+\gamma)\left(7 \gamma^{2}+10 \gamma-29\right)^{2}} \\
& \pi_{2}=32\left(\gamma^{2}+\gamma-2\right)\left(\gamma^{2}-\gamma-6\right) \frac{\alpha^{2}}{(1+\gamma)\left(7 \gamma^{2}+10 \gamma-29\right)^{2}} \\
& \pi_{3}=-8(\gamma+5)\left(\gamma^{2}+4 \gamma-5\right) \frac{\alpha^{2}}{(1+\gamma)\left(7 \gamma^{2}+10 \gamma-29\right)^{2}}
\end{aligned}
$$

By differentiating (19) with respect to $\gamma$ it is easily seen that these are all decreasing in $\gamma$ and they reach zero as $\gamma \rightarrow 1$.

\section{Proof of Proposition 2}

a) To construct best reply functions after the merger we need again to consider the possibility that an ISP sets prices as to "close" one market. In the following we set up the Lagrangians for the two firms and we analyse the conditions under which the internal solutions form an equilibrium for the game.

\section{ISP $1 \& 2$}

The Lagrangian for the merged ISP $1 \& 2$ is given by:

$$
\begin{aligned}
& L_{1 \& 2}=\left[\frac{\alpha}{1+\gamma}-\frac{1}{1-\gamma^{2}}\left(p_{1}+p_{2}\right)+\frac{\gamma}{1-\gamma^{2}}\left(p_{3}+p_{2}\right)+\frac{\alpha}{1+\gamma}-\frac{1}{1-\gamma^{2}}\left(p_{1}+p_{3}\right)+\frac{\gamma}{1-\gamma^{2}}\left(2 p_{2}\right)\right] p_{1}+ \\
& {\left[\left(\frac{\alpha}{1+\gamma}-\frac{1}{1-\gamma^{2}}\left(p_{1}+p_{2}\right)+\frac{\gamma}{1-\gamma^{2}}\left(p_{3}+p_{2}\right)\right)+\left(\frac{\alpha}{1+\gamma}-\frac{1}{1-\gamma^{2}}\left(p_{3}+p_{2}\right)+\frac{\gamma}{1-\gamma^{2}}\left(p_{1}+p_{2}\right)\right)\right] p_{2}+} \\
& +2 p_{2}\left(\frac{\alpha}{1+\gamma}-\frac{1}{1-\gamma^{2}}\left(2 p_{2}\right)+\frac{\gamma}{1-\gamma^{2}}\left(p_{1}+p_{3}\right)\right)+\lambda\left(\frac{\alpha}{1+\gamma}-\frac{1}{1-\gamma^{2}}\left(2 p_{2}\right)+\frac{\gamma}{1-\gamma^{2}}\left(p_{1}+p_{3}\right)\right) \\
& \mu_{1}\left(\frac{\alpha}{1+\gamma}-\frac{1}{1-\gamma^{2}}\left(p_{1}+p_{2}\right)+\frac{\gamma}{1-\gamma^{2}}\left(p_{3}+p_{2}\right)\right)+\mu_{3}\left(\frac{\alpha}{1+\gamma}-\frac{1}{1-\gamma^{2}}\left(p_{1}+p_{3}\right)+\frac{\gamma}{1-\gamma^{2}}\left(2 p_{2}\right)\right)
\end{aligned}
$$

from which we derive the reaction functions:

(11)

$$
\begin{aligned}
& -\gamma \alpha+p_{3} \gamma+\gamma p_{2}+\alpha-p_{2} \quad \text { if } \quad p_{3} \leq \frac{p_{1}+\gamma \alpha-\gamma p_{2}-\alpha+p_{2}}{\gamma} \\
& p_{1}=\left\{- \frac { 1 } { 2 } \gamma \alpha + \frac { 1 } { 4 } p _ { 3 } \gamma + \frac { 3 } { 2 } p _ { 2 } \gamma + \frac { 1 } { 2 } \alpha - \frac { 1 } { 2 } p _ { 2 } - \frac { 1 } { 4 } p _ { 3 } \text { if } \left\{\begin{array}{l}
p_{2}>\frac{1}{2} \frac{\gamma \alpha-\alpha+p_{1}+p_{3}}{\gamma} \\
p_{3}>\frac{p_{1}+\gamma \alpha-\gamma p_{2}-\alpha+p_{2}}{\gamma}
\end{array}\right.\right. \\
& -\gamma \alpha+2 \gamma p_{2}+\alpha-p_{3} \quad \text { if } \quad p_{2} \leq \frac{1}{2} \frac{\gamma \alpha-\alpha+p_{1}+p_{3}}{\gamma}
\end{aligned}
$$

and 


$$
p_{2}=\left\{\begin{array}{ccc}
-\frac{1}{2} \gamma \alpha+\frac{1}{2} p_{1} \gamma+\frac{1}{2} p_{3} \gamma+\frac{1}{2} \alpha & \text { if } & p_{1} \leq \frac{\gamma \alpha-p_{3} \gamma-\alpha+2 p_{2}}{\gamma} \\
-\frac{1}{4} \frac{3 p_{3} \gamma+6 p_{1} \gamma-4 \gamma \alpha-2 p_{1}-p_{3}+4 \alpha}{\gamma-3} & \text { if } & p_{1}>\frac{\gamma \alpha-p_{3} \gamma-\alpha+2 p_{2}}{\gamma}
\end{array}\right.
$$

For ISP three we have:

$$
\begin{aligned}
& L_{3}=\left[\left(\frac{\alpha}{1+\gamma}-\frac{1}{1-\gamma^{2}}\left(p_{3}+p_{2}\right)+\frac{\gamma}{1-\gamma^{2}}\left(p_{1}+p_{2}\right)\right)+\left(\frac{\alpha}{1+\gamma}-\frac{1}{1-\gamma^{2}}\left(p_{1}+p_{3}\right)+\frac{\gamma}{1-\gamma^{2}}\left(2 p_{2}\right)\right)\right] p_{3}+ \\
& +\varphi\left(\frac{\alpha}{1+\gamma}-\frac{1}{1-\gamma^{2}}\left(p_{3}+p_{2}\right)+\frac{\gamma}{1-\gamma^{2}}\left(p_{1}+p_{2}\right)\right)
\end{aligned}
$$

and its reaction function:

$$
p_{3}=\left\{\begin{array}{ccrl}
-\gamma \alpha+p_{1} \gamma+p_{2} \gamma+\alpha-p_{2} & \text { if } & p_{1} \leq \frac{\gamma \alpha-p_{2} \gamma-\alpha+p_{3}+p_{2}}{\gamma} \\
-\frac{1}{2} \gamma \alpha+\frac{1}{4} p_{1} \gamma+\frac{3}{4} \gamma p_{2}+\frac{1}{2} \alpha-\frac{1}{4} p_{2}-\frac{1}{4} p_{1} & \text { if } & p_{1}>\frac{\gamma \alpha-p_{2} \gamma-\alpha+p_{3}+p_{2}}{\gamma}
\end{array}\right.
$$

From (20), (21) and (22) we obtain the candidate ${ }^{19}$ post-merger equilibrium prices:

$$
\begin{aligned}
& p_{1}=\left(\frac{1}{2} \alpha \frac{\left(11 \gamma^{2}+12 \gamma-23\right)}{8 \gamma^{2}+27 \gamma-41}\right) \\
& p_{2}=\left(\frac{7}{2} \alpha \frac{\left(\gamma^{2}+2 \gamma-3\right)}{8 \gamma^{2}+27 \gamma-41}\right) \\
& p_{3}=\left(-5 \alpha \frac{\left(\gamma^{2}-4 \gamma+3\right)}{8 \gamma^{2}+27 \gamma-41}\right)
\end{aligned}
$$

We need however to check if the constraints are binding at these candidate equilibrium prices. We start by checking whether (23) satisfy the constraints in the best reply functions: (20), (21) and (22).

We start from the wireless price $p_{1}$ and check the constraints given by (20).

$$
p_{3}>\frac{\gamma \alpha-\gamma p_{2}-\alpha+p_{1}+p_{2}}{\gamma} \rightarrow p_{1}<-\gamma \alpha+p_{3} \gamma+p_{2} \gamma+\alpha-p_{2}
$$

By substituting (23) into (24) we have:

$$
\frac{1}{2} \alpha \frac{2 \gamma^{2}-59 \gamma+38+19 \gamma^{3}}{8 \gamma^{2}+27 \gamma-41}<0
$$

\footnotetext{
${ }^{19}$ These are only equilibria if there are not binding constraints. We'll see shortly that this is not always the case.
} 
this is not satisfied for $\gamma \geq 0.965$. For these values of $\gamma$ the merged firm will therefore choose a corner solution in setting the price $p_{1}$ for the market in $B_{1}$.

It is easy to show that (24) is the only constraint that is not satisfied at the prices (23) in the three best reply functions

\section{Corner Solutions}

From the previous analysis we have seen that for $\gamma \geq 0.965$ the price $p_{l}$ chosen to close the market in $B_{1}$ is given by the corner solution. In the following we need to verify the new equilibrium prices given the corner best reply for $p_{1}$

$$
p_{1}=-\gamma \alpha+p_{3} \gamma+p_{2} \gamma+\alpha-p_{2}
$$

The new best reply system where $p_{1}$ is chosen from the corner solution while $p_{2}$ and $p_{3}$ are still chosen from the internal best replies will be:

$$
\begin{gathered}
p_{1}=-\gamma \alpha+p_{3} \gamma+p_{2} \gamma+\alpha-p_{2} \\
p_{2}=-\frac{1}{4} \frac{6 p_{1} \gamma-4 \gamma \alpha+3 p_{3} \gamma+4 \alpha-p_{3}-2 p_{1}}{\gamma-3} \\
p_{3}=-\frac{1}{2} \gamma \alpha+\frac{1}{4} p_{1} \gamma+\frac{3}{4} \gamma p_{2}+\frac{1}{2} \alpha-\frac{1}{4} p_{2}-\frac{1}{4} p_{1}
\end{gathered}
$$

providing us with new corner equilibrium prices:

$$
\begin{gathered}
p_{1}=\alpha \frac{\left(\gamma^{3}+17 \gamma^{2}+15 \gamma-33\right)}{17 \gamma^{3}+30 \gamma^{2}-27 \gamma-40} \\
p_{2}=\alpha \frac{\left(11 \gamma^{3}+15 \gamma^{2}-19 \gamma-7\right)}{17 \gamma^{3}+30 \gamma^{2}-27 \gamma-40} \\
p_{3}=\alpha \frac{\left(3 \gamma^{2}+2 \gamma-5\right)}{17 \gamma^{2}+13 \gamma-40}
\end{gathered}
$$

We now need to verify whether substituting (25) into to the $p_{2}$ component of the $I S P 1 \& 2$ best replies, (21) and into ISP three one (22) these conditions will or will not remain satisfied or not.

We start from ISP two: the demand $x_{2}{ }^{A}$ at the new prices given by (25) remains positive.

The same applies for ISP three demand, $x_{3}{ }^{B}$ at the new prices (25). This proves that when $I S P 1 \& 2$ chooses the price $p_{1}$ from its corner best reply and shuts the wireless market in $B_{1}$ while maintaining the wireless open for $A_{1}$ market all the other prices: $p_{2}$ and $p_{3}$ are still derived from internal best replies. This implies that after the merger the corner equilibrium prices are given by (25) for $\gamma \geq 0.965$.

b) An analysis of (25) shows clearly this part of the proposition.

\section{Proof of proposition 3}

a) and b) From the corner equilibrium prices given by equation (25) and from the internal equilibrium ones given by equation (23) we obtain the market share of the wireless provider $I S P$ one at location $B_{I}$ 


$$
\frac{x_{1}{ }^{B}}{x_{1}{ }^{B}+x_{3}{ }^{B}}=\left\{\begin{array}{cccc}
\frac{19 \gamma^{2}+21 \gamma-38}{17 \gamma^{2}+28 \gamma-69} & \text { if } & \gamma \leq 0.965 \\
0 & \text { if } & \gamma>0.965
\end{array}\right.
$$

and the market share of the wireless provider ISP one at location $A_{1}$

$\frac{x_{1}{ }^{A}}{x_{1}{ }^{A}+x_{2}{ }^{A}}=\left\{\begin{array}{lll}\frac{2 \gamma^{2}+13 \gamma-29}{17 \gamma^{2}+28 \gamma-69} & \text { if } & \gamma \leq 0.965 \\ \frac{-5 \gamma^{2}-10 \gamma+3}{5 \gamma^{2}-2 \gamma-23} & \text { if } & \gamma>0.965\end{array}\right.$

The effect of the merger on the market shares is obtained by difference with the pre-merger market shares expressions:

(17) $\Delta \frac{x_{1}{ }^{A}}{x_{1}{ }^{A}+x_{2}{ }^{A}}=\left\{\begin{array}{l}\frac{1}{2} \frac{21 \gamma^{4}+80 \gamma^{3}-14 \gamma^{2}-56 \gamma+17}{\left(17 \gamma^{2}+28 \gamma-69\right)\left(\gamma^{2}-2 \gamma-11\right)} \\ -\frac{1}{2} \frac{5 \gamma^{4}-8 \gamma^{3}-174 \gamma^{2}-144 \gamma+273}{\left(5 \gamma^{2}-2 \gamma-23\right)\left(\gamma^{2}-2 \gamma-11\right)} \quad \text { if } \quad \gamma>0.965\end{array}\right.$

and

$$
\Delta \frac{x_{1}{ }^{B}}{x_{1}{ }^{B}+x_{3}{ }^{B}}=\left\{\begin{array}{ccc}
\frac{7}{2} \frac{3 \gamma^{2}+2 \gamma-1}{\left(17 \gamma^{2}+28 \gamma-69\right)} & \text { if } & \gamma \leq 0.965 \\
-\frac{1}{2} & \text { if } & \gamma>0.965
\end{array}\right.
$$

c), d) and e) The post-merger internal equilibrium prices, when $\gamma \leq 0.965$, are given by (23), the post merger corner prices are given by (25) and the pre-merger ones are given by (17). By subtracting (17) from (23), we obtain the price effect of the merger for $\gamma \leq 0.965$ and we have internal equilibrium prices

$$
\begin{aligned}
\Delta p_{1 \text { int }} & =\frac{3}{2} \alpha \frac{15 \gamma^{4}-14 \gamma^{3}-156 \gamma^{2}+206 \gamma-51}{\left(8 \gamma^{2}+27 \gamma-41\right)\left(7 \gamma^{2}+10 \gamma-29\right)} \\
\Delta p_{2 \text { int }} & =-\frac{1}{2} \alpha \frac{15 \gamma^{4}+112 \gamma^{3}-30 \gamma^{2}+144 \gamma+47}{\left(8 \gamma^{2}+27 \gamma-41\right)\left(7 \gamma^{2}+10 \gamma-29\right)} \\
\Delta p_{3 \text { int }} & =-\alpha \frac{51 \gamma^{4}-28 \gamma^{3}-186 \gamma^{2}+132 \gamma-25}{\left(8 \gamma^{2}+27 \gamma-41\right)\left(7 \gamma^{2}+10 \gamma-29\right)}
\end{aligned}
$$

By subtracting (17) from (25) we obtain the price effect of the merger for $\gamma \geq 0.965$ : 


$$
\begin{gathered}
\Delta p_{1 \text { corn }}=-\alpha \frac{27 \gamma^{5}+67 \gamma^{4}-230 \gamma^{3}-22 \gamma^{2}+715 \gamma-557}{\left(-40-27 \gamma+30 \gamma^{2}+17 \gamma^{3}\right)\left(7 \gamma^{2}+10 \gamma-29\right)} \\
\Delta p_{2 \text { corn }}=\alpha \frac{9 \gamma^{5}+27 \gamma^{4}-178 \gamma^{3}-166 \gamma^{2}+425 \gamma-117}{\left(-40-27 \gamma+30 \gamma^{2}+17 \gamma^{3}\right)\left(7 \gamma^{2}+10 \gamma-29\right)} \\
\Delta p_{3 \text { corn }}=2 \alpha \frac{4 \gamma^{4}-37 \gamma^{3}-29 \gamma^{2}+117 \gamma-55}{\left(17 \gamma^{2}+13 \gamma-40\right)\left(7 \gamma^{2}+10 \gamma-29\right)}
\end{gathered}
$$

d) and e) are clearly derived from (27) and (28).

\section{Proof of proposition 4}

From (23) we obtain the post merger profits when $\gamma \leq 0.965$

$$
\pi_{1 \& 2}=\frac{5}{2} \alpha^{2} \frac{956 \gamma-286 \gamma^{2}+113 \gamma^{4}-372 \gamma^{3}+56 \gamma^{5}-467}{\left(8 \gamma^{2}+27 \gamma-41\right)^{2}\left(\gamma^{2}-1\right)}
$$

and

(21) $\pi_{3}=\alpha^{2} \frac{-50(\gamma-3)\left(\gamma^{2}-4 \gamma+3\right)}{\left(8 \gamma^{2}+27 \gamma-41\right)^{2}(1+\gamma)}$

By using (25) we will have that post-merger profits when $\gamma \geq 0.965$ are given by

$$
\pi_{1 \& 2}=2 \alpha^{2} \frac{851 \gamma-750 \gamma^{2}+217 \gamma^{4}-666 \gamma^{3}+135 \gamma^{5}+213}{\left(17 \gamma^{2}+13 \gamma-40\right)(1+\gamma)^{2}}
$$

and

$$
\pi_{3}=\alpha^{2} \frac{-8(3 \gamma+5)\left(3 \gamma^{2}+2 \gamma-5\right)}{\left(17 \gamma^{2}+13 \gamma-40\right)\left(-40-27 \gamma+30 \gamma^{2}+17 \gamma^{3}\right)}
$$

By subtracting the pre-merger profits from the post merger ones we can derive the merger incentives for the parameter range where the internal solutions are equilibria, (the high differentiation case). By subtracting (19) from (29) and (30) we have:

$$
\begin{aligned}
& \Delta \pi_{1 \& 2}^{h d}=\frac{1}{2}\left(\begin{array}{l}
9624 \gamma^{8}+53981 \gamma^{7}+31205 \gamma^{6}-197227 \gamma^{5} \\
-122843 \gamma^{4}+338863 \gamma^{3}-123113 \gamma^{2}+9183 \gamma+327
\end{array}\right) \\
& \left(\frac{\alpha^{2}}{\left(7 \gamma^{2}+10 \gamma-29\right)^{2}\left(8 \gamma^{2}+27 \gamma-41\right)^{2}(1+\gamma)}\right)
\end{aligned}
$$

and 


$$
\Delta \pi_{3}^{h d}=-2 \alpha^{2} \frac{\left(969 \gamma^{7}-9107 \gamma^{6}-33459 \gamma^{5}+67233 \gamma^{4}+88075 \gamma^{3}-216201 \gamma^{2}+123615 \gamma+21125\right)}{\left(7 \gamma^{2}+10 \gamma-29\right)^{2}\left(8 \gamma^{2}+27 \gamma-41\right)^{2}(1+\gamma)}
$$

By subtracting the sum of the pre-merger profits of ISP one and two (19) from (31) we obtain the incentive for the merger for ISP one and two under low differentiation and corner prices:

$$
\Delta \pi_{1 \& 2}^{l d}=2 \alpha^{2} \frac{\left(\begin{array}{l}
18993 \gamma^{8}+23364 \gamma^{7}-74576 \gamma^{6}-18278 \gamma^{5} \\
+196586 \gamma^{4}-306428 \gamma^{3}-180616 \gamma^{2}+627031 \gamma+288067
\end{array}\right)}{\left(7 \gamma^{2}+10 \gamma-29\right)^{2}\left(17 \gamma^{2}+13 \gamma-40\right)^{2}(1+\gamma)^{2}}
$$

while subtracting from (32) the pre-merger profits of ISP three (19) we obtain the profit effect for ISP three of the merger for ISP one and two under low differentiation and corner prices:

$$
\Delta \pi_{3}^{l d}=-8 \alpha^{2} \frac{\left(\begin{array}{l}
152 \gamma^{7}-754 \gamma^{6}-7181 \gamma^{5} \\
-1217 \gamma^{4}+30094 \gamma^{3}-364 \gamma^{2}-39705 \gamma+18975
\end{array}\right)}{\left(7 \gamma^{2}+10 \gamma-29\right)^{2}\left(17 \gamma^{2}+13 \gamma-40\right)^{2}(1+\gamma)}
$$

From the graph below in Figure 5 we can see that the merged firm, dotted line, has an incentive to merge for $\gamma \leq 0.16$ and $\gamma \geq 0.32$ while firm three, solid line, will benefit from the merger for $\gamma \leq 0.33$ and $\gamma \geq 0.58$.

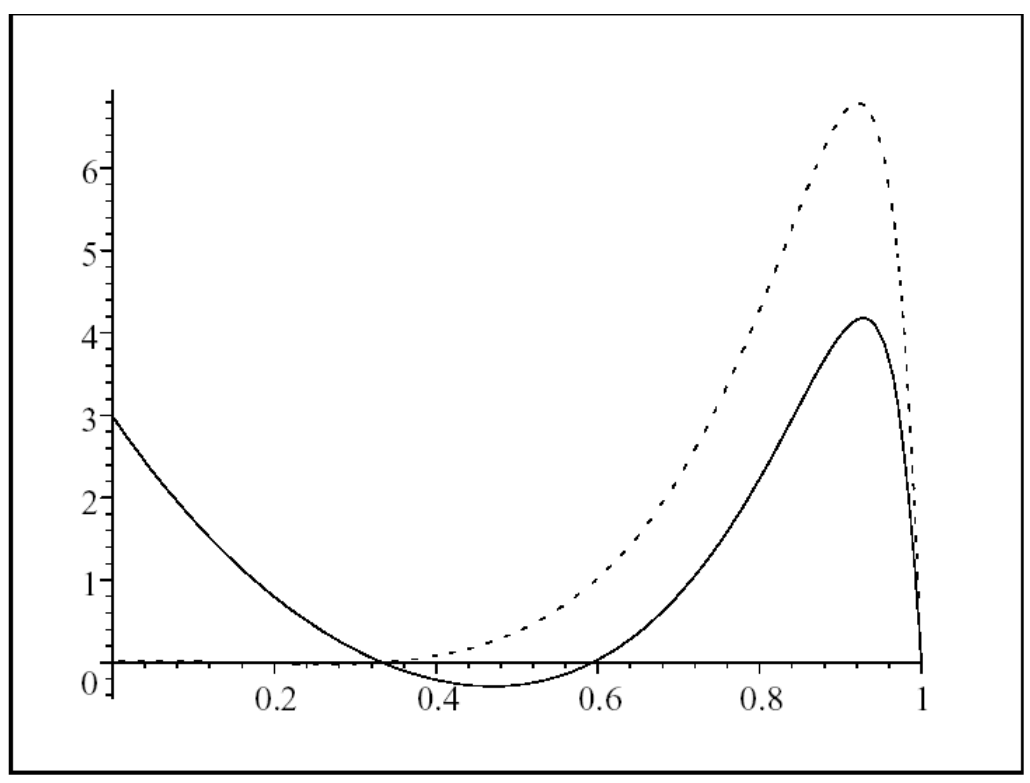

Figure 5: Merger incentives 


\section{Proof of Proposition 5}

From (18) and (3) we obtain the pre-merger consumer surplus for the $B_{1}$ market:

(28) $U_{B}^{\text {premerg }}=\alpha^{2} \frac{\left(\gamma^{2}-2 \gamma-11\right)^{2}}{\left(7 \gamma^{2}+10 \gamma-29\right)^{2}(1+\gamma)}+m$

and similarly from (4) we obtain the pre-merger consumer surplus for the for $A_{1}$ market:

$$
U_{A}^{\text {premerg }}=-\alpha^{2} \frac{\left(3 \gamma^{4}-4 \gamma^{3}+18 \gamma^{2}-36 \gamma-125\right)}{\left(7 \gamma^{2}+10 \gamma-29\right)^{2}(1+\gamma)}+m
$$

For the post-merger consumer surpluses we need to consider the two cases with internal and corner equilibrium prices. From (23) and (3) we obtain the post-merger consumer surplus for the $B_{1}$ market when $\gamma \leq 0.965$

$$
U_{B}{ }^{\text {postmer int }}=-\frac{1}{8} \alpha^{2} \frac{\left(76 \gamma^{4}-623 \gamma^{3}+585 \gamma^{2}+2079 \gamma-2405\right)}{\left(8 \gamma^{2}+27 \gamma-41\right)^{2}(1+\gamma)}+m
$$

and from (23) and (4) we obtain the post-merger consumer surplus for the $A_{l}$ market when $\gamma \leq 0.965$

$$
U_{A}^{\text {postmerint }}=\frac{1}{8} \alpha^{2} \frac{\left(60 \gamma^{4}+619 \gamma^{3}-757 \gamma^{2}+2075 \gamma-2441\right)}{\left(8 \gamma^{2}+27 \gamma-41\right)^{2}(1+\gamma)}+m
$$

Finally from (25) and (3) we obtain the post-merger consumer surplus for the $B_{1}$ market when $\gamma \geq 0.965$.

$$
U_{B}{ }^{\text {postmergcornert }}=-\frac{1}{2} \alpha^{2} \frac{\left(5 \gamma^{2}-2 \gamma-23\right)^{2}}{\left(17 \gamma^{3}+30 \gamma^{2}-27 \gamma-40\right)^{2}}+m
$$

and from (25) and (4) we obtain the post-merger consumer surplus for $A_{1}$ market when $\gamma \geq$ 0.965 .

$U_{A}{ }^{\text {postmergcornert }}=-\frac{1}{2} \alpha^{2} \frac{100 \gamma^{5}+155 \gamma^{4}-420 \gamma^{3}-182 \gamma^{2}+632 \gamma-685}{\left(17 \gamma^{3}+30 \gamma^{2}-27 \gamma-40\right)(\gamma+1)\left(17 \gamma^{3}+30 \gamma^{2}-27 \gamma-40\right)}+m$

Now subtracting (38) from (40) and from (42) we obtain the utility surplus for the $A_{1}$ market: 
(34)

$$
\Delta U_{A}=\left\{\begin{array}{c}
\left(\begin{array}{l}
-1430983 \gamma-314521 \gamma^{4}+1110697 \gamma^{3}+ \\
+626613 \gamma^{2}+4476 \gamma^{8}+47051 \gamma^{7}+ \\
+28351 \gamma^{6}-443565 \gamma^{5}+371881
\end{array}\right) \\
\frac{1}{8} \alpha^{2} \frac{\left(\begin{array}{l}
-885042 \gamma^{2}-1184012 \gamma-171262 \gamma^{6}+ \\
+258846 \gamma^{5}+688580 \gamma^{4}-892194 \gamma^{3}+ \\
+3166 \gamma^{9}-29542 \gamma^{7}+19521 \gamma^{8}-176085
\end{array}\right)}{\left(8 \gamma^{2}+27 \gamma-41\right)^{2}\left(7 \gamma^{2}+10 \gamma-29\right)^{2}} \quad \gamma \leq 0.965 \\
-\frac{1}{2} \alpha^{2} \frac{(13 \gamma)(\gamma+1)\left(7 \gamma^{2}+10 \gamma-29\right)^{2}}{\left(-40-27 \gamma+30 \gamma^{2}+17 \gamma^{3}\right)\left(17 \gamma^{2}+13 \gamma-40\right)} \quad \gamma>0.965
\end{array}\right.
$$

and subtracting (37) from (39) and from (41) we obtain the utility surplus for the $B_{1}$ market

(35) $\Delta U_{B}=$

$$
\left(-\frac{1}{8} \alpha^{2} \frac{\left(\begin{array}{l}
-1010485 \gamma^{3}+486173 \gamma^{4}+1413467 \gamma+ \\
-28207 \gamma^{7}+2188 \gamma^{8}+342025 \gamma^{5}+ \\
-78955 \gamma^{6}-341605-784601 \gamma^{2}
\end{array}\right)}{(\gamma+1)\left(8 \gamma^{2}+27 \gamma-41\right)^{2}\left(7 \gamma^{2}+10 \gamma-29\right)^{2}} \quad \gamma \leq 0.965\right.
$$

$$
-\frac{1}{2\left(\begin{array}{l}
578 \gamma^{9}-2075 \gamma^{8}-20270 \gamma^{7}+ \\
+22170 \gamma^{6}+215710 \gamma^{5}+49444 \gamma^{4}+ \\
-570714 \gamma^{3}-142922 \gamma^{2}+505768 \gamma-57689
\end{array}\right) * \gamma>0.965}
$$

and finally by adding (43) and (44) we obtain the merger total effect on consumer surplus.

(36)

$$
\begin{aligned}
& \int \frac{1}{4} \alpha^{2} \frac{\left(\begin{array}{l}
1060591 \gamma^{3}-400347 \gamma^{4}-1422225 \gamma+37629 \gamma^{7}+ \\
+1144 \gamma^{8}-392795 \gamma^{5}+53653 \gamma^{6}+356743+705607 \gamma^{2}
\end{array}\right)}{(\gamma+1)\left(8 \gamma^{2}+27 \gamma-41\right)^{2}\left(7 \gamma^{2}+10 \gamma-29\right)^{2}} \quad \gamma \leq 0.965
\end{aligned}
$$

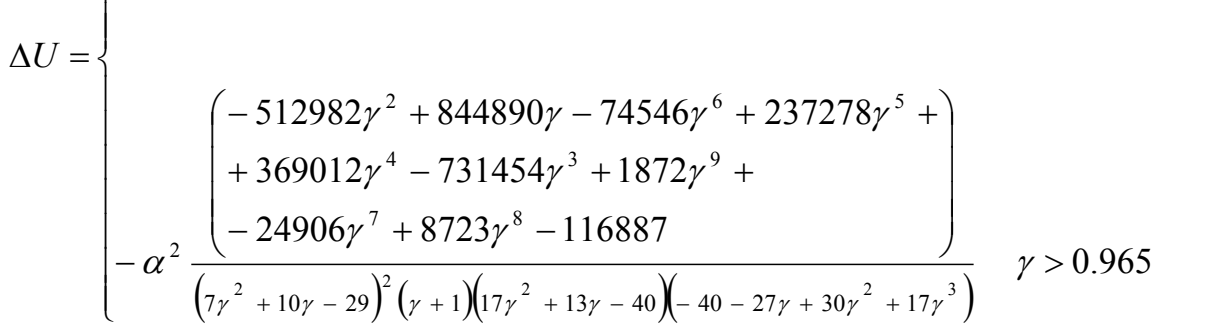


From the profits differentials (33), (34), (35) and (36) we obtain the total profits differential:

(37)

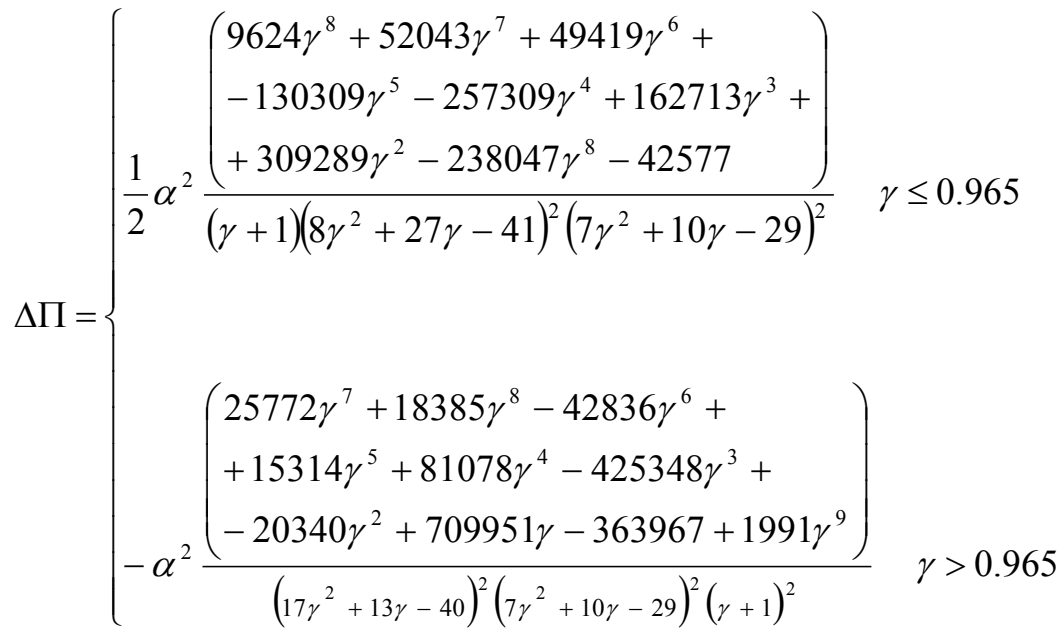

Total welfare is now given by the sum of total profits (46) and total utility (45) differentials

$$
\Delta W=\left\{\begin{array}{l}
\left(\begin{array}{l}
20392 \gamma^{8}+141715 \gamma^{7}+152491 \gamma^{6}+ \\
-653413 \gamma^{5}-914965 \gamma^{4}+1386017 \gamma^{3}+ \\
+1324185 \gamma^{2}-1898319 \gamma^{8}+441897
\end{array}\right) \\
\frac{1}{4} \alpha^{2} \frac{\left(7 \gamma^{2}+10 \gamma-29\right)^{2}(1+\gamma)\left(8 \gamma^{2}+27 \gamma-41\right)^{2}}{\left(7 \gamma^{2}\right.} \quad \gamma \leq 0.965 \\
\alpha^{2} \frac{\left(\begin{array}{l}
2110 \gamma^{9}+28047 \gamma^{8}+76450 \gamma^{7^{6}}+ \\
-11126 \gamma^{6}-206650 \gamma^{5}-206856 \gamma^{4}+ \\
-119242 \gamma^{3}+473302 \gamma^{2}+575012 \gamma-611047
\end{array}\right)}{\left(7 \gamma^{2}+10 \gamma-29\right)^{2}(1+\gamma)\left(17 \gamma^{2}+13 \gamma-40\right)\left(-40-27 \gamma+30 \gamma^{2}+17 \gamma^{3}\right)} \quad \gamma>0.965
\end{array}\right.
$$

The properties of these functions prove the proposition. 


\section{$7 \quad$ Appendix 2}

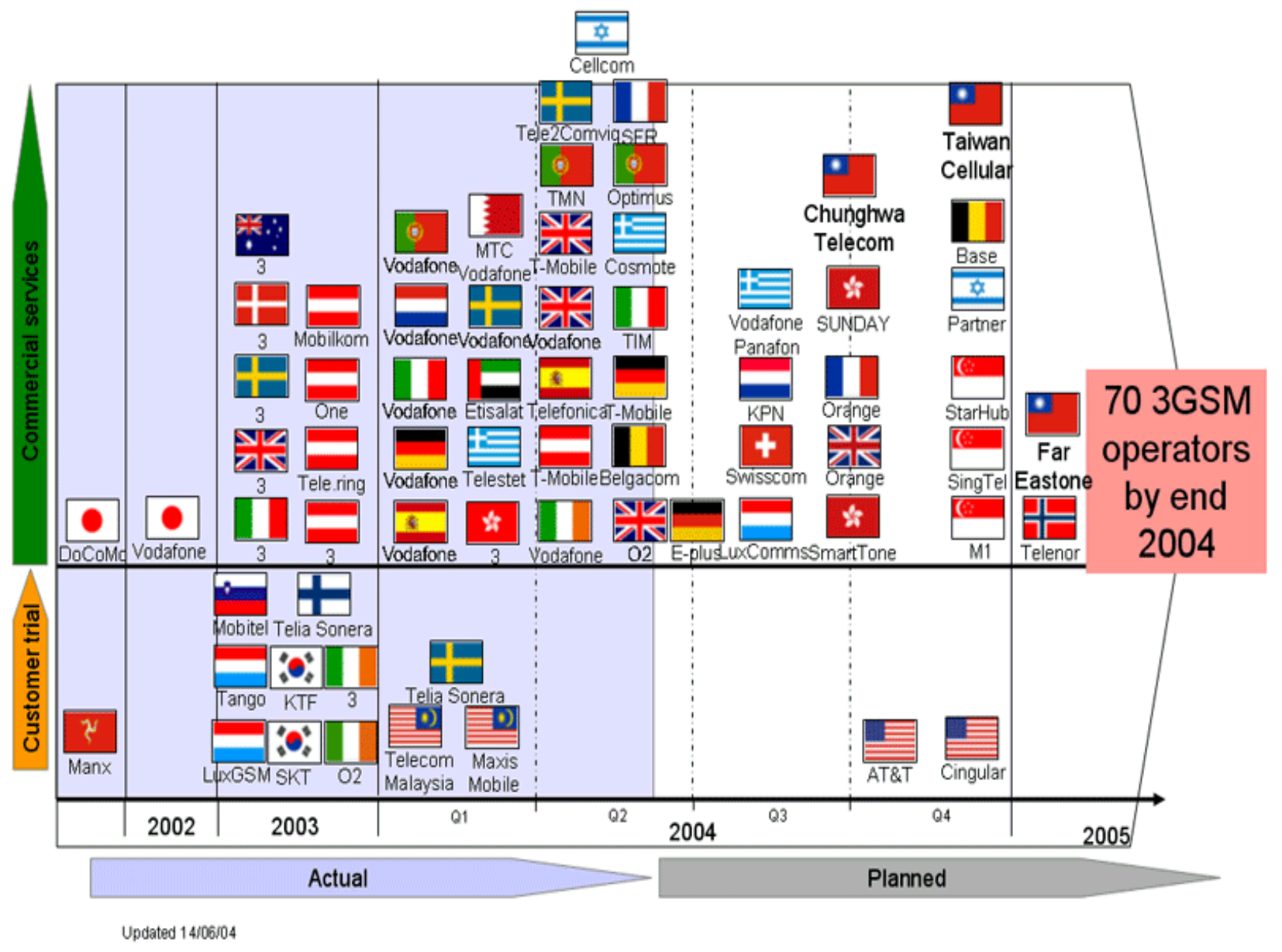

Table A2: Actual \& planned 3 GSM launches worldwide by the end of 2004

Source GSM Association www.gsmworld.com 